\title{
Article
}

\section{Highly Efficient Light-Emitting Diodes of Colloidal Metal- Halide Perovskite Nanocrystals Beyond Quantum Size}

Young-Hoon Kim, Christoph Wolf, Young-Tae Kim, Himchan Cho, Woosung Kwon, Sungan Do, Aditya Sadhanala, Chan Gyung Park, Shi-Woo Rhee, Sang Hyuk Im, Richard H. Friend, and Tae-Woo Lee

ACS Nano, Just Accepted Manuscript • Publication Date (Web): 06 Jun 2017

Downloaded from http://pubs.acs.org on June 7, 2017

\section{Just Accepted}

"Just Accepted" manuscripts have been peer-reviewed and accepted for publication. They are posted online prior to technical editing, formatting for publication and author proofing. The American Chemical Society provides "Just Accepted" as a free service to the research community to expedite the dissemination of scientific material as soon as possible after acceptance. "Just Accepted" manuscripts appear in full in PDF format accompanied by an HTML abstract. "Just Accepted" manuscripts have been fully peer reviewed, but should not be considered the official version of record. They are accessible to all readers and citable by the Digital Object Identifier (DOI®). "Just Accepted" is an optional service offered to authors. Therefore, the "Just Accepted" Web site may not include all articles that will be published in the journal. After a manuscript is technically edited and formatted, it will be removed from the "Just Accepted" Web site and published as an ASAP article. Note that technical editing may introduce minor changes to the manuscript text and/or graphics which could affect content, and all legal disclaimers and ethical guidelines that apply to the journal pertain. ACS cannot be held responsible for errors or consequences arising from the use of information contained in these "Just Accepted" manuscripts. 


\section{Highly Efficient Light-Emitting Diodes of Colloidal Metal-Halide Perovskite Nanocrystals Beyond}

\section{Quantum Size}

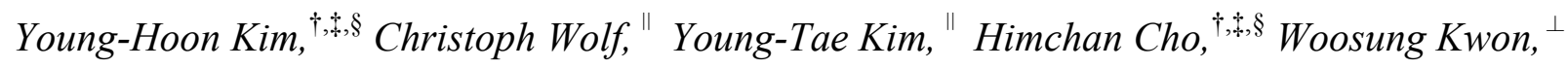
Sungan Do, ${ }^{\nabla}$ Aditya Sadhanala, ${ }^{\triangle}$ Chan Gyung Park, ${ }^{\prime}$ Shi-Woo Rhee, ${ }^{\nabla}$ Sang Hyuk Im, ${ }^{\circ}$ Richard H. Friend, $\triangle$ Tae-Woo Lee ${ }^{* \dagger, t, \S}$

${ }^{\dagger}$ Department of Materials Science and Engineering, Seoul National University, 1 Gwanak-ro, Gwanak-gu, Seoul 08826, Republic of Korea

${ }^{*}$ Research Institute of Advanced Materials, Seoul National University, 1 Gwanak-ro, Gwanakgu, Seoul 08826, Republic of Korea

${ }^{\S}$ BK21 PLUS SNU Materials Division for Educating Creative Global Leaders, Seoul National University, 1 Gwanak-ro, Gwanak-gu, Seoul 08826, Republic of Korea

" Department of Materials Science and Engineering, Pohang University of Science and Technology (POSTECH), Pohang, Gyungbuk 790-784, Republic of Korea

${ }^{\perp}$ Department of Chemical and Biological Engineering, Sookmyung Women's University, 100 Cheongpa-ro 47-gil, Yongsan-gu, Seoul, Republic of Korea 04310 
$\nabla$ Department of Chemical Engineering, Pohang University of Science and Technology (POSTECH), 77 Cheongam-Ro, Nam-Gu, Pohang, Gyeongbuk 790-784, Republic of Korea ${ }^{\triangle}$ Cavendish Laboratory, University of Cambridge, JJ Thomson Avenue, Cambridge CB3 OHE, $U K$

${ }^{\circ}$ Department of Chemical Engineering, College of Engineering, Kyung Hee University, 1 Seochon-dong, Giheung-gu, Youngin-si, Gyeonggi-do 446-701, Republic of Korea

KEYWORDS: perovskite nanocrystal, quantum size, light-emitting diodes, hole injection layer, electroluminescence

Corresponding Author

*E-mail: twlees@snu.ac.kr, taewlees@gmail.com 


\section{ABSTRACT}

Colloidal metal-halide perovskite quantum dots (QDs) with a dimension $<$ exciton Bohr diameter $D_{\mathrm{B}}$ (quantum size regime) emerged as promising light emitters due to their spectrally-narrow light, facile color tuning and high photoluminescence quantum efficiency (PLQE). However, their size-sensitive emission wavelength and color purity, and low electroluminescence (EL) efficiency are still challenging tasks. Here, we demonstrate highly efficient light-emitting diodes (LEDs) based on the colloidal perovskite nanocrystals $\left(\mathrm{NCs}\right.$ ) in a dimension $>D_{B}$ (regime beyond quantum size) by using multi-functional buffer hole injection layer (Buf-HIL). The perovskite NCs with a dimension $>D_{B}$ show a size-irrespectively high color-purity and PLQE by managing the recombination of excitons occurred at surface traps and inside the NCs. The BufHIL composed of poly(3,4-ethylenedioxythiophene)/poly(styrene sulfonate) (PEDOT:PSS) and perfluorinated ionomer induces uniform perovskite particle films with complete film coverage and prevents exciton quenching at the PEDOT:PSS/perovskite particle film interface. With these strategies, we achieved very high PLQE ( 60.5\%) in compact perovskite particle films without any complex post-treatments and multi-layers, and high current efficiency of $15.5 \mathrm{~cd} / \mathrm{A}$ in the LEDs of colloidal perovskite NCs, even in a simplified structure, which is the highest efficiency to date in green LEDs that use colloidal organic-inorganic metal-halide perovskite nanoparticles including perovskite QDs and NCs. These results can help to guide development of various lightemitting optoelectronic applications based on perovskite NCs. 
Metal-halide perovskite emitters emerged as promising light emitters because they are inexpensive, can emit spectrally-narrow light (full width at half maximum (FWHM) $20 \mathrm{~nm}$ ) which is irrespective to their crystal size and have facile color tuning and comparable ionization energy $I E$, and electron affinity levels with those of organic charge transporting layers. ${ }^{1-4}$ However, electroluminescence (EL) efficiencies based on conventional polycrystalline perovskite bulk films are limited by the low exciton binding energy $E_{b}$ of the perovskite bulk films (e.g. $76 \mathrm{meV}$ for methylammonium lead bromide $\left(\mathrm{CH}_{3} \mathrm{NH}_{3} \mathrm{PbBr}_{3}\right)$ ) and low photoluminescence quantum efficiency (PLQE) at room temperature (RT), by the presence of electrical shunt paths caused by the rough surface and pinholes in perovskite films, and by the large number of intrinsic defects caused by imperfect micrometer-sized cubic crystals. 5,6

Recently, the potential of polycrystalline perovskite bulk film emitters has been demonstrated by confining the exciton in small perovskite nano-grains $(\sim 100 \mathrm{~nm})$, reducing the exciton diffusion length $L_{D}(\sim 67 \mathrm{~nm})$ and leakage current in devices by fabricating uniform perovskite film; ${ }^{2,4}$ these results showed that the photoluminescence (PL) and EL efficiencies of perovskite emitters can be increased if $E_{b}$ can be further increased and $L_{D}$ can be decreased by reducing the grain size.

However, a more-ideal approach to achieve high $E_{b}$ and low $L_{D}$ in perovskite emitters is to effectively confine the excitons in the form of nanometer-scale $(<20 \mathrm{~nm})$ colloidal perovskite nanoparticles (NPs) rather than in polycrystalline perovskite bulk films with large grain size $(0.1$ $10 \mu \mathrm{m})$. These perovskite NPs are in totally different research sub-fields from polycrystalline perovskite bulk films, and have completely different approach methods and fabrication processes. $^{7}$ Thus, development and application of perovskite NPs as emitters should be considered separately from those of polycrystalline perovskite bulk films. Furthermore, 
perovskite NPs can have higher possibility to improve the EL efficiency of perovskite emitters than can polycrystalline perovskite bulk films because perovskite NPs themselves showed much higher PLQE than did polycrystalline perovskite bulk films. ${ }^{2,6,7}$ Therefore, solution processed light-emitting diodes (LEDs) based on perovskite NPs with size-irrespectively high color-purity and efficiency should be studied.

Perovskite NPs can be divided into two different regime: (i) perovskite quantum dots (QDs) with a dimension $<$ exciton Bohr diameter $D_{\mathrm{B}}$ (quantum size regime) and (ii) unexplored perovskite nanocrystals (NCs) with a dimension $>D_{\mathrm{B}}$ (regime beyond quantum size). Perovskite QDs with size less than $D_{\mathrm{B}}(<10 \mathrm{~nm})$ showed high $E_{b}$, low $L_{D}$ and thereby achieved high PLQE at RT. ${ }^{6-12}$ In addition, the amenability of perovskite QDs to colloidal synthesis gives various advantages such as compatibility with shape- and size-engineering, compositional diversity, excellent solubility in common organic solvents (e.g. toluene and chlorobenzene), and the possibility of post-synthetic reversible chemical exchange of halide anion. ${ }^{6-12}$ However, these studies do not exploit the great advantage that electronic properties of perovskite emitters are determined by the unit crystal's structure rather than by the particle size, and still suffer strong dependence of emission wavelength and color purity on the QD size, as do inorganic QDs. ${ }^{13}$ Therefore, perovskite NCs with dimension $>D_{\mathrm{B}}$ in which wavelength and color-purity of emitted light are not affected by the crystal size should be evaluated.

Furthermore, uniform perovskite NC films should also be fabricated to demonstrate the high efficiency LEDs. However, perovskite QD or nanoplate films on conventional poly(3,4ethylenedioxythiphene):poly(styrene sulfonate) (PEDOT:PSS) hole injection layer (HIL) induced the inhomogeneous surface morphology with pinholes and aggregated QDs or nanoplates, thus, reduced the luminescence efficiency in LEDs. ${ }^{14}$ Recently, uniform perovskite 
QD or nanoplate films and potential of high efficiency LEDs were demonstrated by covering the perovskite nanoplate films with organic host materials, or by using trimethylaluminum vaporbased crosslinking methods, or by using dip-coating methods to fabricate the QD films on PEDOT:PSS/poly(9-vinylcarbazole) multi-layer. ${ }^{14-16}$ Very recently, efficient LEDs based on colloidal perovskite nanoplate films were also demonstrated (external quantum efficiency EQE = $0.23 \%$ for blue-sky, $E Q E=0.038 \%$ for violet and $E Q E=2.31 \%$ for green $),{ }^{17,18}$ and the highest current efficiency $C E$ reported so far in green LEDs that use colloidal organic-inorganic metal halide perovskite NP layers is $11.49 \mathrm{~cd} / \mathrm{A} .{ }^{19}$ The exciton quenching by PEDOT:PSS at the PEDOT:PSS/perovskite NP interface in the devices can still be significant. ${ }^{3}$ The device efficiency can be further improved by overcoming the severe exciton quenching at the PEDOT:PSS/perovskite NP interface and by fabricating the uniform perovskite NP films with complete film coverage. ${ }^{20}$ Therefore, homogeneous perovskite NC films without any additional processes and multi-layers need to be fabricated and the exciton quenching at the PEDOT:PSS/perovskite NC interface should be prevented to further improve the EL efficiency of perovskite NC-LEDs. ${ }^{20}$

Here, we report the highly efficient perovskite NC-LEDs by two important strategies: i) synthesizing the $\mathrm{CH}_{3} \mathrm{NH}_{3} \mathrm{PbBr}_{3} \mathrm{NP}$ emitters with dimension $>D_{\mathrm{B}}$ (perovskite NCs) and ii) using multi-functional buffer hole injection layer (Buf-HIL) (Figure 1a,b). Perovskite NCs (i.e., perovskite NPs with dimensions $>D_{\mathrm{B}}$ ) unlike QDs lead to size-insensitivity of emission wavelength and of color purity, due to crystal structure-dependent electronic band structures. ${ }^{1,2}$ Furthermore, they can also achieve high PLQE and EL efficiency because NCs have lower surface area to volume ratio, and therefore, show less trap-assisted recombination occurred at the surface traps and smaller amount of insulating ligand in film states than do perovskite QDs 
(dimension $\left.<D_{\mathrm{B}}\right) .{ }^{6,8,21,22}$ Buf-HIL also induces uniform perovskite particle films with complete film coverage. Furthermore, they can prevent the exciton quenching at the PEDOT:PSS/perovskite particle film interface. ${ }^{3}$ With these strategies, we achieved a very high PLQE $(\sim 60.5 \%)$ in compact perovskite particle films without any complex post-treatments and high $C E=15.5 \mathrm{~cd} / \mathrm{A}$ in perovskite NC-LEDs even in a simplified device structure (anode/BufHIL/perovskite NCs/1,3,5-tris(N-phenylbenzimiazole-2-yl)benzene (TPBI)/cathode).

\section{RESULTS AND DISCUSSION}

We used solubility-difference-assisted crystallization at RT to synthesize $\mathrm{CH}_{3} \mathrm{NH}_{3} \mathrm{PbBr}_{3} \mathrm{NPs}$ with various size including QDs and NCs that incorporate two ligands: (1) n-hexylamine to prevent the direct crystallization of $\mathrm{CH}_{3} \mathrm{NH}_{3} \mathrm{PbBr}_{3}$ precursors into large (micrometer) crystals when they are mixed with "bad" solvent (e.g. toluene), and (2) oleic acid to suppress the reaggregation of synthesized perovskite NPs and to control the crystallization rate and size of crystal by adhering to the surfaces of perovskite NPs. ${ }^{6,8,23}$ This adhesion is facilitated by charge equilibrium between carboxyl groups of oleic acid and amine groups of methyl-ammonium in perovskite NPs. ${ }^{6}$ Oleic acid can serve as an emulsifier and surface-capping agent by anchoring to the surface amine groups of perovskite NPs. Thus, we can control the size of perovskite NPs by adjusting the amount of oleic acid: increasing the amount of emulsifier-oleic acid reduces the duration of reaction and thus decreases the NP size from $\sim 35 \mathrm{~nm}$ to $\sim 3 \mathrm{~nm}$ and reduces the size deviations (Figure 1c,d and Figure S1). ${ }^{23-25}$ High-resolution transmission electron microscopy (HR-TEM) and fast Fourier Transform (FFT) image showed a good crystalline structure with inter-planar distances of $2.68 \AA$ and $2.95 \AA$, which correspond to the (210) and (200) crystal planes, respectively (Figure 1e); this observation indicates that perovskite NPs had a cubic 
$P m \overline{3} m$ phase. These crystal planes are consistent with the X-ray diffraction (XRD) peaks, which can be interpreted using Bragg's law (Figure S2). The broad XRD peaks according to the DebyeScherrer expression further confirm that the perovskite NPs are small. ${ }^{8}$ Elementary mapping images measured by energy dispersive spectroscopy (EDS) further confirm that $\mathrm{Pb}$ and $\mathrm{Br}$ atoms which constitute the perovskite crystals are uniformly distributed in their perovskite NPs (Figure 1f).

By fitting an equivalent circuit model of impedance spectroscopy data, we extracted exciton Bohr radius $r_{\mathrm{B}} \approx 5 \mathrm{~nm}$, which is in accordance with previous literature (Figure S3). ${ }^{26-28}$ This result indicates that perovskite NPs $<10 \mathrm{~nm}$ (i.e., QDs) showed blue-shifted PL spectrum (484 $\mathrm{nm}$ for 5-nm QDs and $470 \mathrm{~nm}$ for 3-nm QDs, respectively) due to quantum-size effect, and broadened PL spectrum (FWHM: $35 \mathrm{~nm}$ for 5-nm QDs and $30 \mathrm{~nm}$ for 3-nm QDs, respectively) possibly due to the size distribution and to defect states or shallow traps in the large surface regions (Figure 2a,b). ${ }^{22}$ These blue-shifted PL spectrum of perovskite QDs indicated the increasing PL peak energy with decreasing dimension below quantum size $\left(<D_{\mathrm{B}}\right)$; these are consistent with the effective mass theory for semiconductor QDs (Figure S4). ${ }^{26,27,29}$ The PL spectrum of perovskite NPs $>10 \mathrm{~nm}$ (i.e., NCs) showed sharp peaks (FWHM $\sim 23 \mathrm{~nm}$ ) at $\sim 515$ nm. These perovskite NCs are beyond quantum-size regime and their spectrum is unaffected by their size because their electronic band structures depend on the unit crystal structure rather than on particle size. Perovskite NPs of size $<D_{\mathrm{B}}$ (i.e., 5-nm and 3-nm QDs) showed a gradually blue shift in emission under UV illumination as the particle size decreased due to quantum-size effect (Inset of Figure 2b, S4). The PL peak positions of all perovskite NPs remained constant regardless of the excitation wavelength; this result indicates that they have a single lowest 
excited state $\left(\mathrm{S}_{1}\right)$, do not have any other PL centers (e.g. from ligand) and meet Kasha's rule (Figure S5).

Perovskite NCs with size $\gtrsim D_{\mathrm{B}}$ (i.e., 11-27 nm) showed the highest PLQE $(\sim 72 \%)$ among perovskite NPs (Figure 2c). The high PLQE of perovskite NCs is due to the increased $E_{b}$ and spatial exciton confinement in small NCs of size close to $D_{\mathrm{B}}$, which increase the electron-hole wavefunction overlap and radiative recombination by reducing the thermal ionization and delocalization of excitons. ${ }^{6-10}$ In contrast, perovskite QDs with size $<D_{\mathrm{B}}$ showed gradually decreasing PLQE from $\sim 65 \%$ for 5-nm QDs to $\sim 62 \%$ for 3-nm QDs. We attribute this decrease to the increase in trap-assisted recombination of excitons at surface traps due to larger surface-tovolume ratio because trap-assisted recombination is mainly related to the non-radiative recombination..$^{6,8,21,22,26}$ Due to the competing processes between thermal ionization $\left(>>D_{\mathrm{B}}\right)$ and trapping of charge carriers at surface traps $\left(<D_{\mathrm{B}}\right)$, perovskite NCs with size $\gtrsim D_{\mathrm{B}}$ showed the highest PLQE and sharp spectrum (small FWHM) with constant PL position irrespective of particle size and size distribution, and thus can maximize the EL efficiency in LEDs.

To further understand the dynamics of exciton in perovskite NPs according to the size difference, we used time-correlated single-photon counting (TCSPC) to measure the PL lifetime of NPs (Figure 2d). All samples showed a much shorter average lifetime $\tau_{\text {avg }}$ than did bulk perovskite films $(\sim 100 \mathrm{~ns}){ }^{2}$ the reduction in lifetime indicates that PL decay of perovskite NPs mainly occurs by geminate electron-hole recombination due to increasing $E_{b}$ and electron-hole overlap, rather than by free-carrier recombination. ${ }^{6,7}$ As the size of perovskite NPs decreased from 35-nm NPs to 3-nm NPs, PL lifetime gradually decreased from 15.49 ns to 6.68 ns due to i) enhanced spatial confinement of electron-hole pairs inside the perovskite NPs and ii) increasing trap-assisted recombination of carriers at the surface traps. ${ }^{2,21,22,26}$ In the perovskite NCs with 
size $\geq D_{B}(\sim 10 \mathrm{~nm})$ (regime beyond quantum size), spatial confinement of electron-hole pairs mainly occurred with decreasing the NP size, thus, PLQE of NPs gradually increased to a certain size close to $D_{B}$ (Figure 2c). However, in the perovskite QDs with size $<D_{B}$ (quantum size regime), trap-assisted recombination of carriers at the surface traps, which can mainly induce the non-radiative recombination of carriers, more severely occurred due to their large surface-tovolume ratio, thus, PLQE of NPs tended to decrease with decreasing NP size (Figure 2c). Thus, our perovskite NPs with size $\sim D_{B}$ showed highest PLQE ( 72\%).

To measure the energy band structure of perovskite NPs, we conducted temperature $(T)$ dependent PL (Figure S6, S7), ultraviolet photoelectron spectroscopy (UPS) (Figure S8) and ultraviolet (UV)/visible absorption spectroscopy (Figure S9) of various NPs. As perovskite NP size decreased, $E_{b}, I E$ and optical band gap (i.e., absorption onset) tended to increase from $\sim 153$ $\mathrm{meV}, \sim 5.7 \mathrm{eV}$ and $\sim 2.35 \mathrm{eV}$ for $35-\mathrm{nm} \mathrm{NPs}$ to $\sim 319 \mathrm{meV}, \sim 5.95 \mathrm{eV}$ and $\sim 2.59 \mathrm{eV}$ for $3-\mathrm{nm}$ NPs, respectively. Thus, band gap (i.e., gap between valence band maximum and conduction band minimum) also gradually increased from $\sim 2.51 \mathrm{eV}$ for $35-\mathrm{nm}$ perovskite NPs to $\sim 2.91 \mathrm{eV}$ for 3nm NPs (Figure 3a); these are similar to the inorganic QDs $\left(<D_{\mathrm{B}}\right) .{ }^{30}$ These increasing band-gap of perovskite QDs $(<10 \mathrm{~nm})$ induced the quantum size effect and blue-shifted PL (Figure 2a,b and Figure S4,5).

Furthermore, to relatively investigate the size reduction of perovskite NPs, we compared the peak intensity of $\mathrm{C}, \mathrm{O}, \mathrm{Br}, \mathrm{Pb}$ and $\mathrm{N}$ atoms in X-ray photoelectron spectroscopy (XPS) measurements. As perovskite NP size decreased, the $\mathrm{C}$ and $\mathrm{O}$ peaks relatively increased, but the $\mathrm{Br}, \mathrm{Pb}$ and $\mathrm{N}$ peaks gradually decreased (Figure 3b,c and Figure $\mathrm{S} 10$ ). ${ }^{6,31} \mathrm{We}$ attribute these opposing changes to the increasing surface area, which contains a surface-capping agent (oleic acid), compared to the decreasing core perovskite nanostructure $\left(\mathrm{CH}_{3} \mathrm{NH}_{3} \mathrm{PbBr}_{3}\right)$. The surface 
characteristics were also identified using Fourier transform infrared (FT-IR) spectroscopy data (Figure 3d). We can clearly detect the C-N stretches $\left(1020-1200 \mathrm{~cm}^{-1}\right)$ and C-O bend (1200$1300 \mathrm{~cm}^{-1}$ ), which indicate the presence of hexylamine and oleic acid, respectively. The N-H stretches $\left(3000-3300 \mathrm{~cm}^{-1}\right), \mathrm{C}-\mathrm{H}$ bend $\left(1450-1550 \mathrm{~cm}^{-1}\right)$ and C-H stretches $\left(2850-3000 \mathrm{~cm}^{-1}\right)$ also confirmed the presence of organic ligands (e.g. hexylamine and oleic acid) and perovskite crystals $\left(\mathrm{CH}_{3} \mathrm{NH}_{3} \mathrm{PbBr}_{3}\right)$.

Perovskite particle films on Buf-HIL composed of poly $(3,4-$ ethylenedioxythiphene):poly(styrene sulfonate) (PEDOT:PSS) and perfluorinated polymeric acid (PFI), tetrafluoroethylene-perfluoro-3,6-dioxa-4-methyl-7-octene-sulfonic acid copolymer, showed a uniform surface with root-mean-square roughness $r_{r m s}=3.46 \mathrm{~nm}$ (Figure 3e). The uniform surface of Buf-HIL/perovskite particle films can reduce electrical shunt paths and leakage current in LED devices. However, perovskite particle films on conventional PEDOT:PSS HIL showed sparsely-coated and aggregated particle structure, and induced the severe exciton quenching at the interface (Figure S11). ${ }^{3}$ Furthermore, gradually increasing PFI concentration in Buf-HIL from bottom surface to top surface due to its self-organization can induce gradually increasing work-function of Buf-HIL from $\sim 5.2 \mathrm{eV}$ at bottom surface to $\sim 5.95$ $\mathrm{eV}$ at top surface and thus, improve the hole injection capability to perovskite particle emitting layer (EML) (Figure 3a). ${ }^{3}$ Large proportion of PFI on top of Buf-HIL can also prevent the exciton quenching at the PEDOT:PSS/perovskite particle film interface. ${ }^{3}$ Therefore, Buf-HIL can increase the EL efficiencies of perovskite NP-LEDs not only by facilitating the hole injection and preventing exciton quenching at the PEDOT:PSS/perovskite particle film interface, but also by inducing the uniform perovskite particle films possibly due to their low surface energy $(\sim 23$ $\mathrm{mN} / \mathrm{m}$ ) (Figure S11 and Table S1).,32 
Uniform perovskite particle films on Buf-HIL maintained the sharp green PL peak of perovskite particle films at both RT and low $T$ (Figure S12). Thus, perovskite particle films on Buf-HIL also maintained high PLQE ( $60.5 \%)$ without any complex post-treatment; this value is only slightly lower than that of NPs in solution (PLQE 72\%) and significantly higher than that of polycrystalline perovskite bulk film without an additional treatment (PLQE $~ 2.4 \%$, average size $\gtrsim \mu \mathrm{m})$. The perovskite particle films on Buf-HIL also showed very uniform and bright PL under excitation at $\lambda=350 \mathrm{~nm}$ (Figure 3f).

LEDs based on perovskite NCs $\gtrsim D_{\mathrm{B}}(11-27 \mathrm{~nm})$ showed luminescence efficiencies $(C E \sim$ 4.88-6.02 cd/A and EQE 1.04-1.26\%) which are higher than those of other devices (Figure 4a-c and Figure S13). The LEDs based on perovskite NPs $>>D_{\mathrm{B}}$ or $<D_{\mathrm{B}}$ exhibited poorer luminescence efficiencies, which are consistent with PLQE trend of emitting NPs although some agglomeration of perovskite NPs occurs during the five-times spin-coating process of the NP solution (Figure S14). These low luminescence efficiencies of LEDs based on as-synthesized perovskite NPs $\gg>D_{\text {B }}$ can be mainly ascribed to the large particle size in the deposited particle films (Figure S14), whereas the low efficiency in LEDs with as-synthesized NPs $<D_{\mathrm{B}}$ is mainly due to large amount of insulating ligand in the deposited particle films (Figure 3b,c and Figure S10). These luminescence efficiencies of LEDs based on various perovskite NPs are well reproduced in ten randomly-selected LED devices and also in LEDs without thermal annealing, although the overall luminescence efficiencies of LEDs without thermal annealing were much lower than those with thermal annealing, possibly due to the residual solvent and imperfect crystallinity in perovskite particle films (Figure S15,16). ${ }^{33}$ 
To further confirm the size effects of as-synthesized perovskite NPs on the deposited perovskite particle films, we measured the $\tau_{\text {avg }}$ of the deposited particle films. As the size of as-synthesized perovskite NPs increased, $\tau_{\text {avg }}$ of the deposited perovskite particle films, as measured at the maximum PL peak ( $\sim 520 \mathrm{~nm})$, gradually increased from $43.75 \mathrm{~ns}$ for particle films fabricated by as-synthesized 3-nm NPs to $95.97 \mathrm{~ns}$ for particle films formed by as-synthesized 35-nm NPs (Figure S17,18a). These results correspond well with the $\tau_{\text {avg }}$ of as-synthesized perovskite NP solutions (Figure 2d), and thus confirm that the size of deposited perovskite particles in films was affected by the size of as-synthesized NPs. $\tau_{\text {avg }}$ increased with increasing detectionwavelength in perovskite particle films fabricated using as-synthesized NPs with large size (i.e., 27 and $35 \mathrm{~nm}$ ), but not in particle films fabricated using as-synthesized NPs with small size (i.e., 3 and $5 \mathrm{~nm}$ ) (Figure S18b-f). These increasing $\tau_{\text {avg }}$ with increasing detection-wavelength may be due to the large size distribution in perovskite particle films fabricated using large as-synthesized NPs. ${ }^{34}$ These results also concur with the size distribution of the as-synthesized perovskite NPs (Figure 1d), and thus indicate that the relationship between size distribution and the particle size of deposited particle films correspond to the same relationships in as-synthesized NPs. These results confirm that to maximize the both PLQE of perovskite NPs and luminescence efficiencies of NP based LEDs, the size of as-synthesized NPs should be controlled to be $\approx D_{\mathrm{B}}$. Furthermore, these luminescence efficiencies of perovskite NC-LEDs are also much higher than those using conventional PEDOT:PSS $(C E \sim 0.117 \mathrm{~cd} / \mathrm{A})$ due to the homogeneous perovskite particle films with full coverage on Buf-HIL, improved hole injection capability and prevented exciton quenching at the PEDOT:PSS/perovskite particle film interface by using Buf-HIL (Table S1, Figure S11,19). The average EML thickness of LEDs using 11-nm perovskite NCs is $\sim 15 \mathrm{~nm}$ in 
which we assume that the average thickness of perovskite NP films in NP-LEDs in Figure 4a-c is around 1-1.5 monolayers (Inset of Figure 4c).

We further optimized the luminescence efficiencies of perovskite NC-LEDs by increasing the thickness of 11-nm NC EML to $\sim 30 \mathrm{~nm}$. The perovskite NC-LEDs exhibited very high maximum $C E$ of $15.5 \mathrm{~cd} / \mathrm{A}, E Q E$ of $5.09 \%$ and power efficiency $P E$ of $12.17 \mathrm{~lm} / \mathrm{W}$ without complex post-treatment and additional layer (Figure 4d-f and Figure S20a,b). To our best knowledge, these efficiencies are the best in green LEDs based on colloidal organic-inorganic metal-halide perovskite NPs, and comparable to the highest efficiencies in green LEDs based on colloidal all-inorganic metal-halide perovskite NPs with NP size $<10 \mathrm{~nm}(E Q E \sim 6.27 \%, C E \sim$ $13.3 \mathrm{~cd} / \mathrm{A}, P E \sim 5.24 \mathrm{~lm} / \mathrm{W})$ including perovskite QDs and NCs to date. ${ }^{35,36}$ The perovskite NCLEDs exhibited very bright green emission (Inset of Figure 4f). The sharp EL spectrum (FWHM $\sim 22 \mathrm{~nm}$ ) did not change with applied bias; this stability indicates that the Buf-HIL and electroninjecting TPBI layer efficiently facilitate charge injection into the perovskite particle layer and confine the injected holes and electrons in the EML (Figure S20c). The Commission Internationale de l'Éclairage coordinates were $(0.088,0.711)$ which located outside of the National Television System Committee standard colors (Inset of Figure S20c). ${ }^{30}$

\section{CONCLUSIONS}

In conclusion, we fabricated the high-efficiency perovskite $\mathrm{NC}$-LEDs with $C E=15.5 \mathrm{~cd} / \mathrm{A}$ without any complex post-treatments and multi-layers, which is the highest efficiency in green LEDs using organic-inorganic metal-halide perovskite NPs including perovskite QDs and NCs to date. To achieve that high EL efficiency in perovskite NPs, we i) synthesized perovskite NC 
emitters with a dimension $\geq D_{\mathrm{B}}$. Perovskite NCs can provide size-insensitively high color-purity and high efficiency by preventing charge trapping at the surface defects or traps in NPs of size $<$ $D_{\mathrm{B}}$ and thermal ionization of excitons in NPs of size $>>D_{\mathrm{B}}$, respectively. Furthermore, we ii) used Buf-HIL which can efficiently prevent the exciton quenching at the PEDOT:PSS/perovskite particle film interface. Buf-HIL can also make the highly uniform perovskite particle films with complete film coverage, thus, maximize the PLQE ( $60.5 \%)$ and EL efficiency of perovskite particle films.

This demonstration of high efficiency perovskite NC-LEDs based on semiconducting perovskite NPs with size $\geq D_{\mathrm{B}}$ and Buf-HIL suggests a simple route to develop high-efficiency NP-LEDs that use inexpensive and size-insensitive emitters with high color purity and high efficiency, while inorganic QDs and perovskite QDs show size-sensitive emission colors and size-distribution-dependent color purity. Considering the low-cost processability, suitable dimension for fine control for massive synthesis, size-insensitive light emission, applicability to many optoelectronics, and high PLQE of perovskite NCs, these methods described here can help to guide development of various light-emitting optoelectronic applications based on perovskite NCs. 


\section{METHODS AND EXPERIMENTAL DETAILS}

Preparation of $\mathbf{C H}_{3} \mathbf{N H}_{3} \mathbf{B r}$ precursor. $\mathrm{CH}_{3} \mathrm{NH}_{3} \mathrm{Br}$ was synthesized by reacting $50 \mathrm{~mL} \mathrm{HBr}$ (48\% in water, Aldrich) with $30 \mathrm{~mL}$ of methylamine ( $40 \%$ in methanol, Junsei Chemical Co. Ltd.) in a $250-\mathrm{mL}$ round-bottom flask. After evaporating the solvents, we collected the white precipitates. Then, we purified and recrystallized the products by using ethanol and diethyl ether. Synthesis of Perovskite Nanoparticles. We dissolved $0.6 \mathrm{mmol}$ of $\mathrm{CH}_{3} \mathrm{NH}_{3} \mathrm{Br}, 0.8 \mathrm{mmol}$ of $\mathrm{PbBr}_{2}$, and $80 \mu \mathrm{L}$ n-hexylamine in $20 \mathrm{~mL} \mathrm{DMF}$ to form a clear transparent precursor solution. Then, $1 \mathrm{~mL}$ of precursor solution was dropped into a $5 \mathrm{ml}$ of toluene solution containing a predissolved oleic acid with different amount from $5 \mu \mathrm{L}$ to $100 \mu \mathrm{L}$ with vigorous stirring. The solution changed to yellow-green color immediately upon mixing. The solution was centrifuged at $3000 \mathrm{rpm}$ for $10 \mathrm{~min}$ to remove large particles which settled down to the bottom of falcon-tube. Then, we collected the perovskite NP solution by pouring the upper part solution into other vial except aggregated particles. 
LEDs Fabrication. ITO patterned glasses were sonicated twice in acetone and once in 2isopropanol for $15 \mathrm{~min}$ each, then boiled in 2-isopropanol for $30 \mathrm{~min}$ and dried in an oven. After these steps, the glasses were treated with ozone for $10 \mathrm{~min}$ to make the surface hydrophilic. On the ozone-treated surface, Buf-HILs were spin-coated to make a layer of 40-nm thickness, then baked at $150{ }^{\circ} \mathrm{C}$ for $30 \mathrm{~min}$. Each sample was transferred into a glove box and perovskite NP solutions which were dissolved in toluene were spin-coated with $3000 \mathrm{rpm}$ for $90 \mathrm{~s}$. The above spin-coating procedure was repeated five times. To fabricate the thicker perovskite NP films, we spin-coated NP solutions with higher concentration, which were synthesized by dripping higher concentrated precursor solution $\left(3.45 \mathrm{mmol}\right.$ of $\mathrm{CH}_{3} \mathrm{NH}_{3} \mathrm{Br}, 4.6 \mathrm{mmol}$ of $\mathrm{PbBr}_{2}$, and $460 \mu \mathrm{L}$ hexylamine in $20 \mathrm{~mL}$ DMF) into oleic acid-dissolved toluene with vigorous stirring. After they were baked at $90^{\circ} \mathrm{C}$ for $10 \mathrm{~min}$, they were transferred to the vacuum chamber. Then, TPBI (50 $\mathrm{nm}), \mathrm{LiF}(1 \mathrm{~nm})$ and $\mathrm{Al}(100 \mathrm{~nm})$ were thermally deposited sequentially in a high-vacuum $\left(<10^{7}\right.$ Torr) at rates of $1 \AA / \mathrm{s}, 0.1 \AA / \mathrm{s}$ and $3 \AA / \mathrm{s}$, respectively.

LEDs Characterization. The current-voltage-luminance of the LEDs with pixel area of $4 \mathrm{~mm}^{2}$ were measured using a Keithley 2400 source measurement and a Minolta CS2000 spectroradiometer.

Time-correlated single photon counting (TCSPC) Measurement. A picosecond-pulse laser head (LDH-P-C-405B, PicoQuant) with 405-nm excitation wavelength, 150 -fs pulse width and $40-\mathrm{MHz}$ repetition rate were used as an excitation source. The PL emission was spectrally resolved by using a monochromator (SP-2155, Acton). A TCSPC module (PicoHarp, PicoQuant) with a MCP-PMT (R3809U-50, Hamamatsu) was used for ultrafast detection.

Photoluminescence (PL) and photoluminescence quantum efficiency (PLQE) Measurement. PL spectra and matrix were measured using a JASCO FP8500 spectrofluorometer. PLQEs of 
perovskite NP solutions were measured using the same spectrofluorometer equipped with a 100mm integrating sphere (ILF-835) and calculated by Jasco SpectraManager II Software. PLQEs of perovskite NC films were measured using a 407-nm blue diode laser with an excitation power of $\sim 15 \mathrm{~mW}$ as an excitation source and Andor iDus DU490A InGaAs as a detector.

Transmission electron microscopy (TEM) Measurement. Perovskite NP solution in toluene were dropped on the carbon coated copper mesh grids (CF200-Cu) which were purchased from electron microscopy sciences (EMS). Transmission electron microscopy (TEM) experiment was performed using a JEOL-JEM 2100F operating at an acceleration voltage of $200 \mathrm{kV}$. 
a)

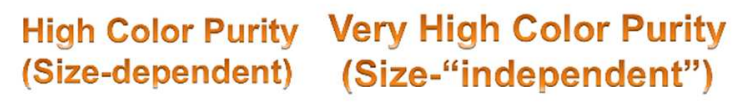

b)

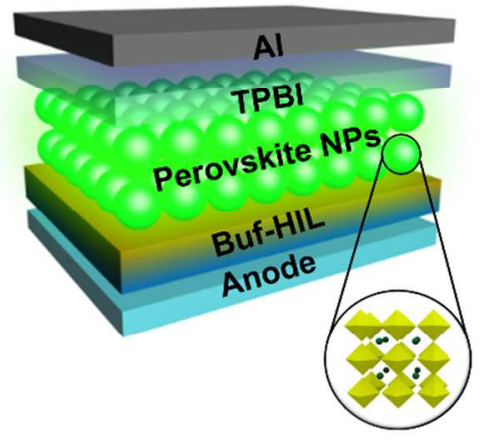

d)

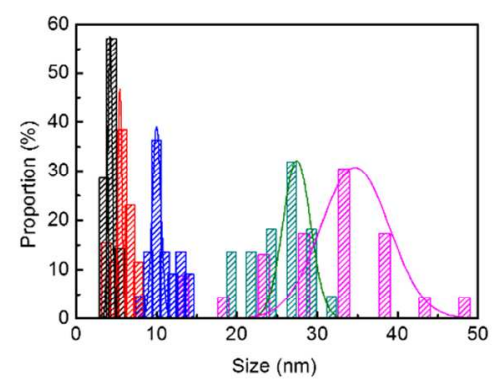

e) c)
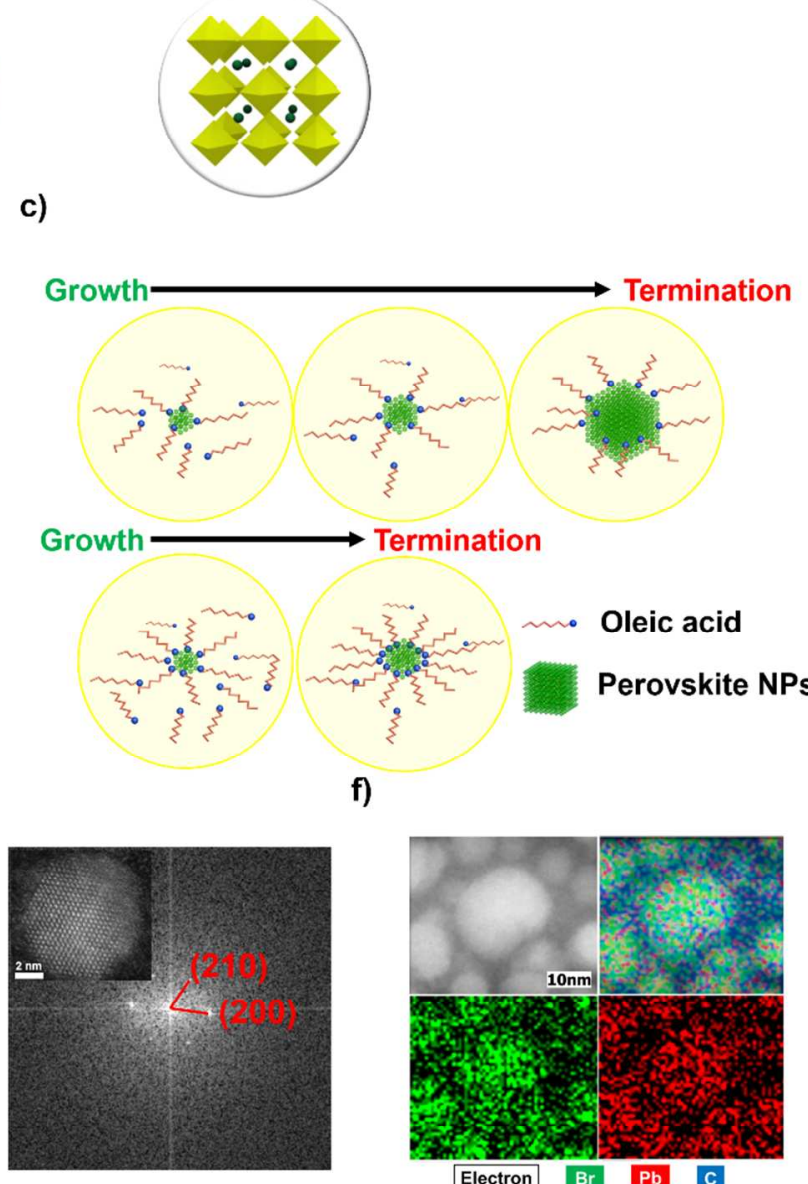

f)

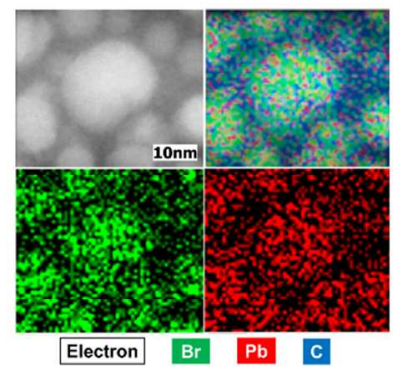

Figure 1. a) Dimension distributions of inorganic QDs, perovskite QDs and perovskite NCs, b) device architecture of perovskite NP-LEDs, c) schematic illustration of size-controllable perovskite NP synthesis, d) size distribution histogram of perovskite NPs according to the different amount of ligand quantity, e) fast Fourier Transform (FFT) pattern and high-resolution TEM image (inset), and f) elemental mapping of perovskite NPs. 


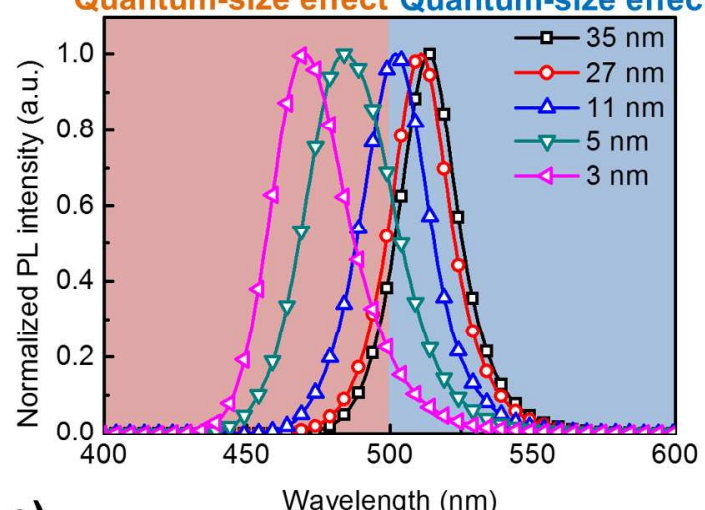

b)
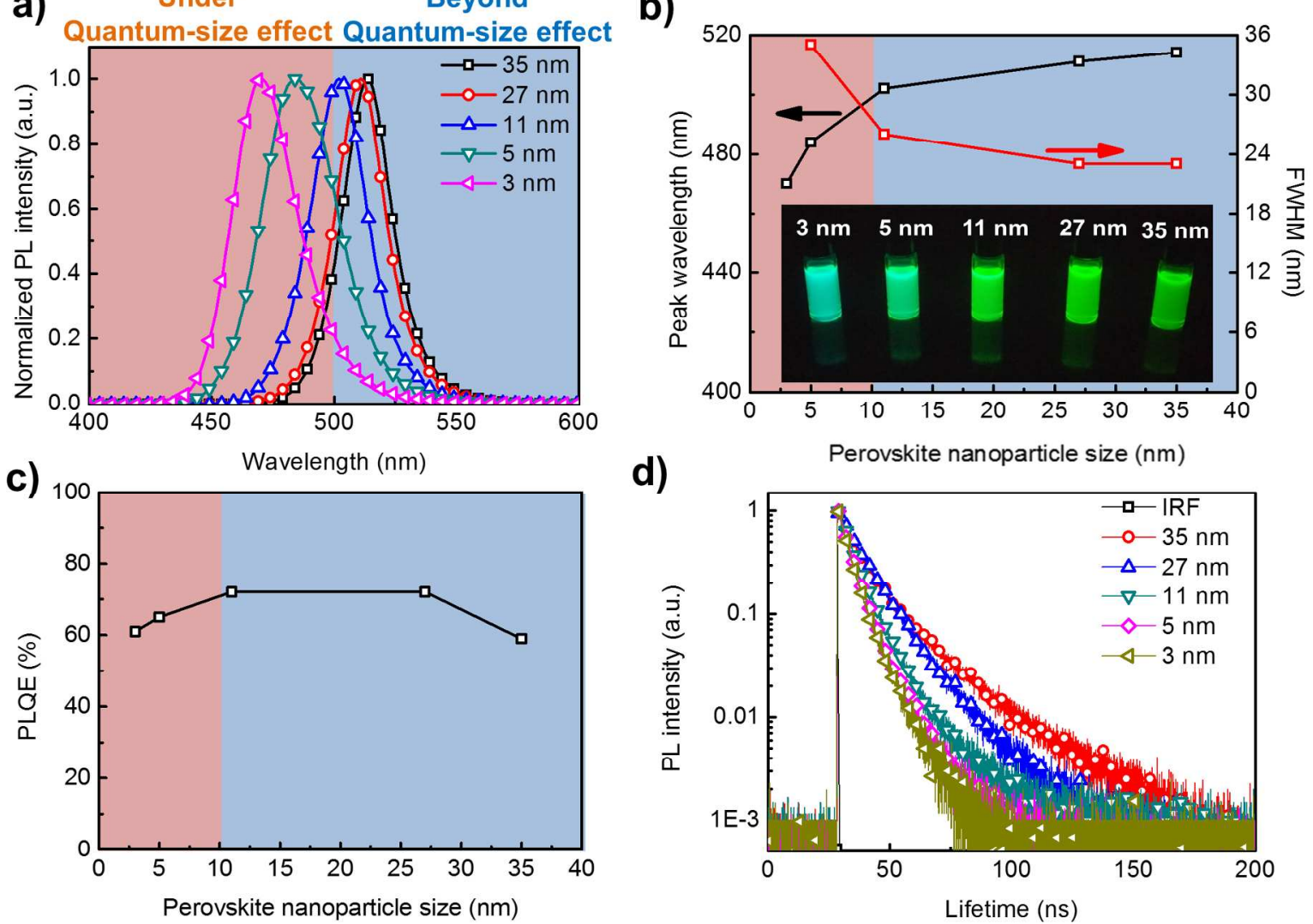

d)

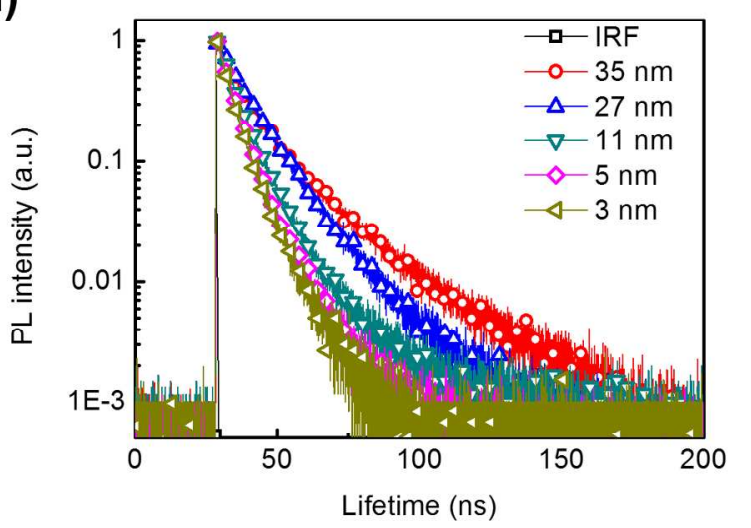

Figure 2. a) PL spectra of perovskite NPs, b) maximum PL peak wavelengths and FWHM of perovskite NPs and photograph of perovskite NPs under $\lambda=350-\mathrm{nm}$ Xe lamp (inset), c) PLQE of the perovskite NPs under 400-nm excitation and d) PL lifetime curves of perovskite NPs obtained from TCSPC. 
a)

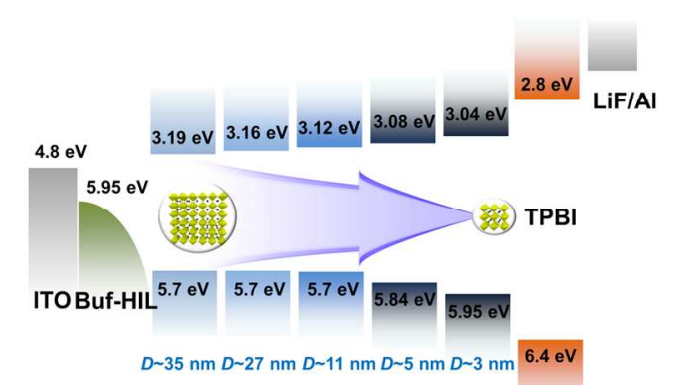

c)

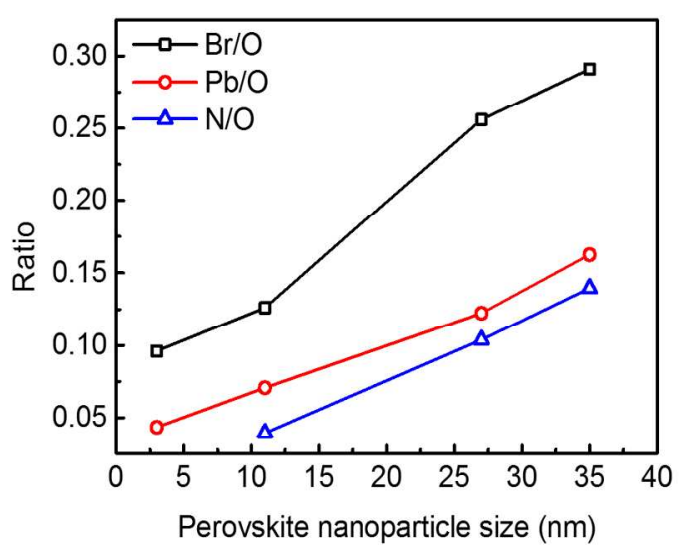

e)

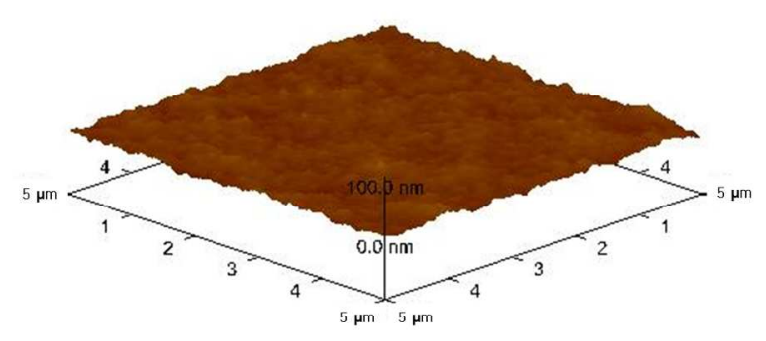

RMS $3.46 \mathrm{~nm}$ b)

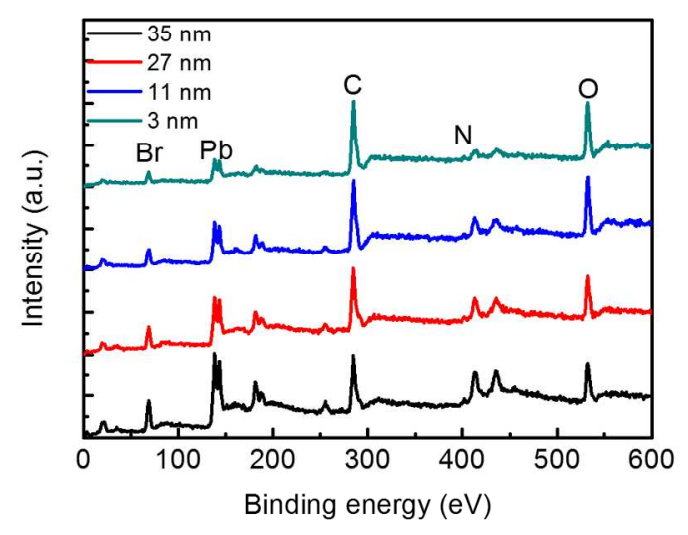

d)

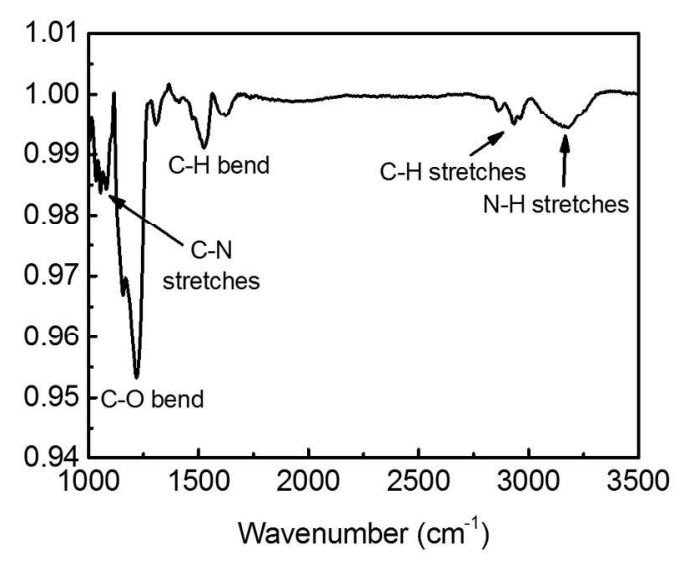

f)

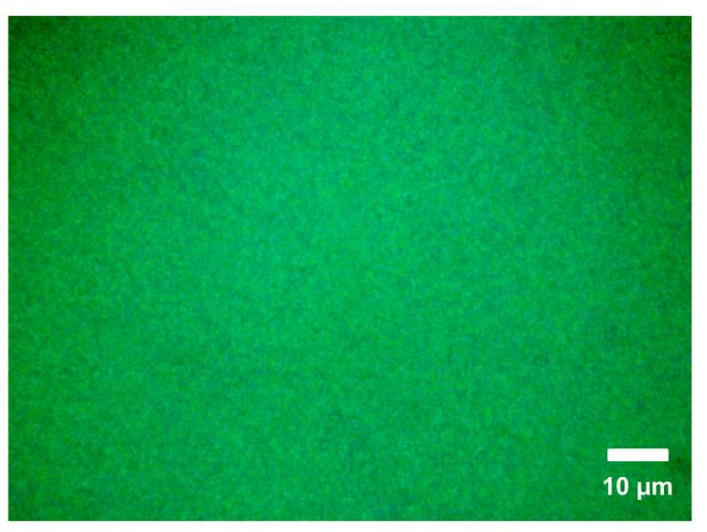

Figure 3. a) Energy band diagram of perovskite NP-LEDs, b) XPS survey spectra of perovskite $\mathrm{NPs}, \mathrm{c}) \mathrm{Br} / \mathrm{O}, \mathrm{Pb} / \mathrm{O}$ and $\mathrm{N} / \mathrm{O}$ ratio of perovskite NPs, d) FT-IR spectrum of perovskite particle films, e) AFM image of Buf-HIL/perovskite particle films and f) fluorescence microscope image of Buf-HIL/perovskite particle films under $\lambda=350$-nm excitation. 
a)

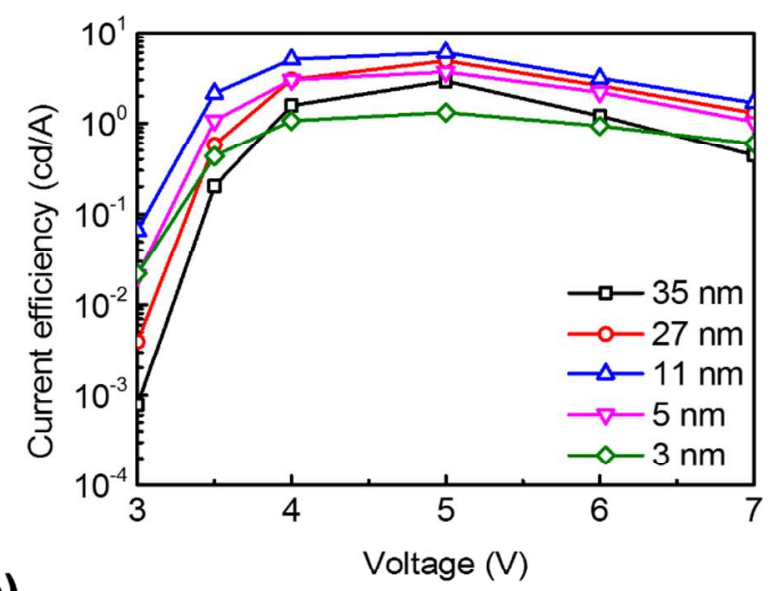

c)

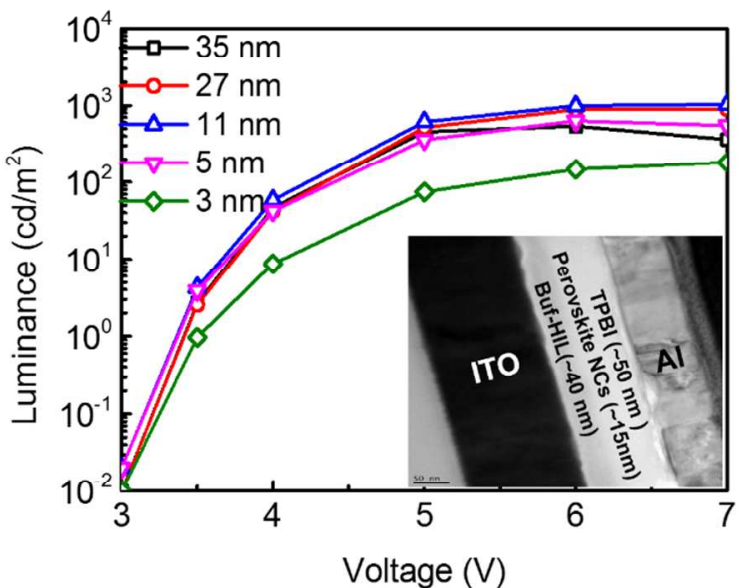

e)

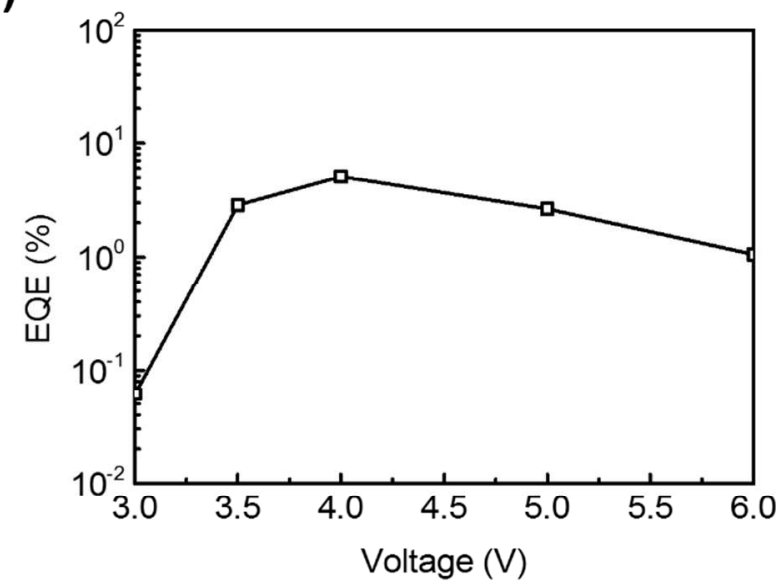

b)

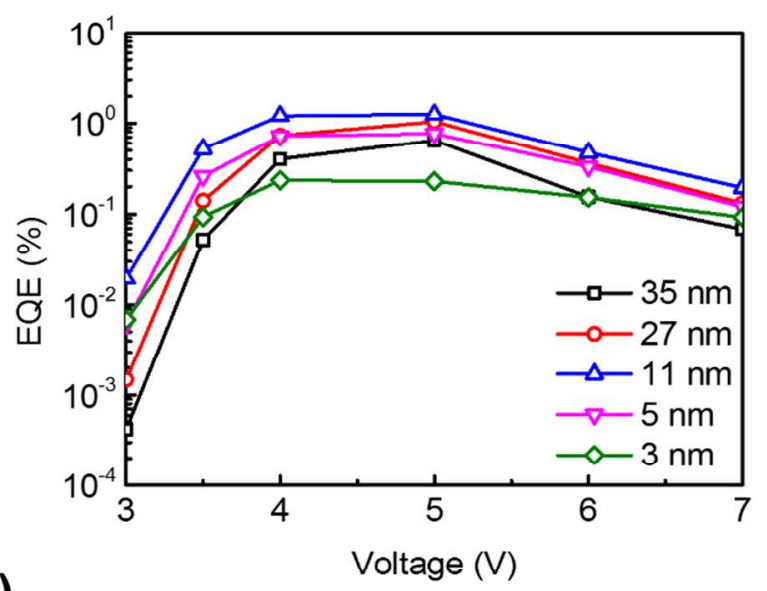

d)

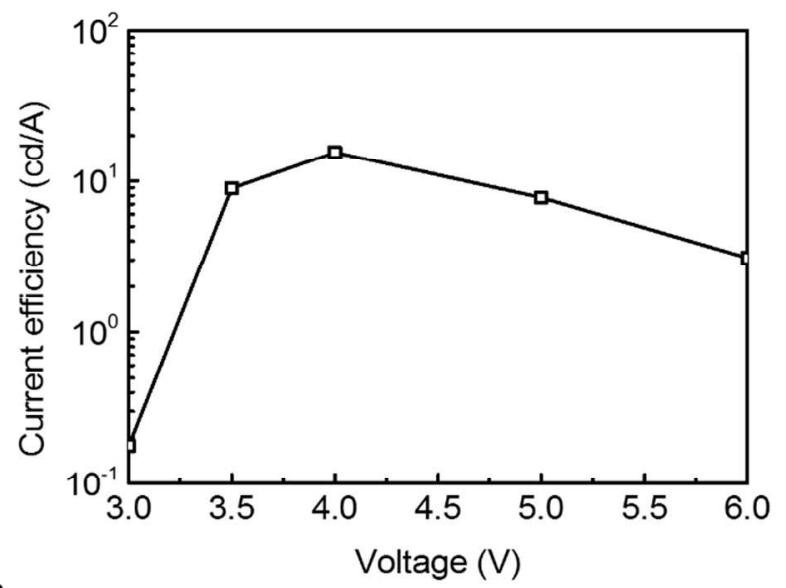

f)

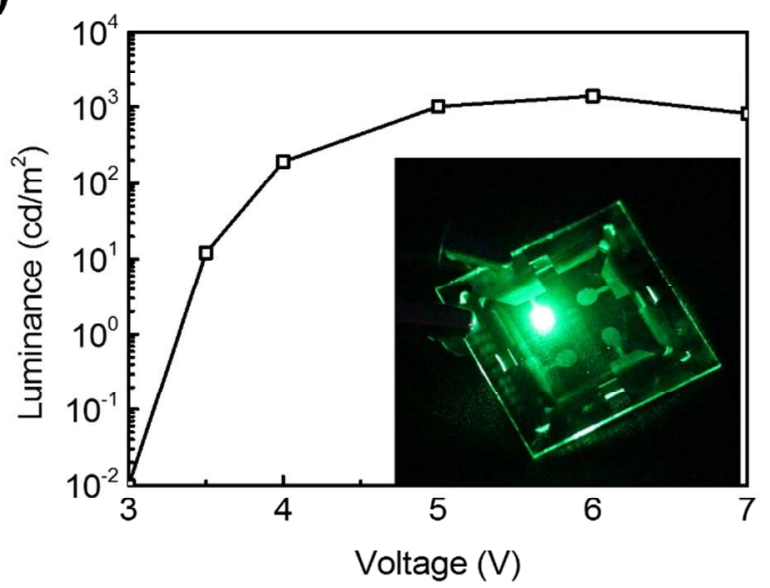

Figure 4. a) $\mathrm{CE}$ characteristics, b) $\mathrm{EQE}$ characteristics, c) luminance characteristics of perovskite NP-LEDs using various NPs and cross-sectional TEM image (inset); d) CE characteristics, e) EQE characteristics and f) luminance characteristic and photograph (inset) of perovskite NC-LEDs with 30-nm thick NC layer. 


\title{
ASSOCIATED CONTENT
}

\section{AUTHOR INFORMATION}

\section{Corresponding Author}

*E-mail: twlees@snu.ac.kr, taewlees@gmail.com

\begin{abstract}
Notes
The authors declare no competing financial interest.
\end{abstract}

\section{ACKNOWLEDGMENTS}

This work was supported by Samsung Research Funding Center of Samsung Electronics under Project Number SRFC-MA-1402-07. This work was also supported by the National Research Foundation of Korea (NRF) grant funded by the Korea government (Ministry of Science, ICT \& Future Planning) (Grant No. NRF-2016R1A3B1908431). A.S. and R.H.F. gratefully acknowledge the support from EPSRC and Indo-UK APEX project. All data are available in the main text and the supplementary materials.

\section{Supporting Information.}

This Supporting Information is available free of charge on the ACS Publications website via the Internet at http://pubs.acs.org.

Additional TEM, XRD, PL matrix, temperature dependent PL, UPS, UV/vis absorption, AFM, and LED performance. 


\section{REFERENCES}

1. Tan, Z.-K.; Moghaddam, R. S.; Lai, M. L.; Docampo, P.; Higler, R.; Deschler, F.; Price, M.; Sadhanala, A.; Pazos, L. M.; Credgington, D.; Hanusch, F.; Bein, T.; Snaith, H. J.; Friend, R. H. Bright Light-Emitting Diodes Based on Organometal Halide Perovskite. Nat. Nanotechnol. 2014, 9, 687-692.

2. Cho, H.; Jeong, S.-H.; Park, M.-H.; Kim, Y.-H.; Wolf, C.; Lee, C.-L.; Heo, J. H.; Sadhanala, A.; Myoung, N.; Yoo, S.; Im, S. H.; Friend, R. H.; Lee, T.-W. Overcoming the Electroluminescence Efficiency Limitations of Perovskite Light-Emitting Diodes. Science $\mathbf{2 0 1 5}, 350,1222-1225$.

3. Kim, Y.-H.; Cho, H.; Heo, J. H.; Kim, T.-S.; Myoung, N.; Lee, C.-L.; Im, S. H.; Lee, T.-W. Multi-Colored Organic/Inorganic Hybrid Perovskite Light-Emitting Diodes. Adv. Mater. 2015, 27, 1248-1254.

4. Xiao, Z.; Kerner, R. A.; Zhao, L.; Tran, N. L.; Lee, K. M.; Koh, T.-W.; Scholes, G. D.; Rand, B. P. Efficient Perovskite Light-Emitting Diodes Featuring Nanometre-Sized Crystallites. Nat. Photon. 2017, 11, 108-115.

5. Heo, J. H.; Song, D. H.; Im, S. H. Planar $\mathrm{CH}_{3} \mathrm{NH}_{3} \mathrm{PbBr}_{3}$ Hybrid Solar Cells with 10.4\% Power Conversion Efficiency, Fabricated by Controlled Crystallization in the Spin-Coating Process. Adv. Mater. 2014, 26, 8179-8183.

6. Zhang, F.; Zhong, H.; Chen, C.; Wu, X.-G.; Hu, X.; Huang, H.; Han, J.; Zou, B.; Dong, Y. Brightly Luminescent and Color-Tunable Colloidal $\mathrm{CH}_{3} \mathrm{NH}_{3} \mathrm{PbX}_{3}(\mathrm{X}=\mathrm{Br}, \mathrm{I}, \mathrm{Cl})$ Quantum Dots: Potential Alternatives for Display Technology. ACS Nano 2015, 9, 4533-4542. 
7. Kim, Y.-H.; Cho, H.; Lee, T.-W. Metal Halide Perovskite Light Emitters. Proc. Natl. Acad. Sci. U. S. A. 2016, 113, 11694-11702.

8. Huang, H.; Susha, A. S.; Kershaw, S. V.; Hung, T. F.; Rogach, A. L. Control of Emission Color of High Quantum Yield $\mathrm{CH}_{3} \mathrm{NH}_{3} \mathrm{PbBr}_{3}$ Perovskite Quantum Dots by Precipitation Temperature. Adv. Sci. 2015, 2, 1500194.

9. Zheng, K.; Zhu, Q.; Abdellah, M.; Messing, M. E.; Zhang, W.; Generalov, A.; Niu, Y.; Ribaud, L.; Canton, S. E.; Pullerits, T. Exciton Binding Energy and the Nature of Emissive States in Organometal Halide Perovskites. J. Phys. Chem. Lett. 2015, 6, 2969-2975.

10. Schmidt, L. C.; Pertegás, A.; González-Carrero, S.; Malinkiewicz, O.; Agouram, S.; Espallargas, G. M.; Bolink, H. J.; Galian, R. E.; Pérez-Prieto, J. Nontemplate Synthesis of $\mathrm{CH}_{3} \mathrm{NH}_{3} \mathrm{PbBr}_{3}$ Perovskite Nanoparticles. J. Am. Chem. Soc. 2014, 136, 850-853.

11. Kim, Y.; Yassitepe, E.; Voznyy, O.; Comin, R.; Walters, G.; Gong, X.; Kanjanaboos, P.; Nogueira, A. F.; Sargent, E. H. Efficient Luminescence from Perovskite Quantum Dot Solids. ACS Appl. Mater. Interfaces 2015, 7, 25007-25013.

12. Jang, D. M.; Park, K.; Kim, D. H.; Park, J.; Shojaei, F.; Kang, H. S.; Ahn, J.-P.; Lee, J. W.; Song, J. K. Reversible Halide Exchange Reaction of Organometal Trihalide Perovskite Colloidal Nanocrystals for Full-Range Band Gap Tuning. Nano Lett. 2015, 15, 5191-5199.

13. Anikeeva, P. O.; Halpert, J. E.; Bawendi, M. G.; Bulović, V. Quantum Dot Light-Emitting Devices with Electroluminescence Tunable over the Entire Visible Spectrum. Nano Lett. 2009, 9, 2532-2536. 
14. Ling, Y.; Yuan, Z.; Tian, Y.; Wang, X.; Wang, J. C.; Xin, Y.; Hanson, K.; Ma, B.; Gao, H. Bright Light $\square$ Emitting Diodes Based on Organometal Halide Perovskite Nanoplatelets. Adv. Mater. 2016, 28, 305-311.

15. Li, G.; Rivarola, F. W. R.; Davis, N. J. L. K.; Bai, S.; Jellicoe, T. C.; Peña, F. D. L.; Hou, S.; Ducati, C.; Gao, F.; Friend, R. H.; Greenham, N. C.; Tan, Z.-K. Highly Efficient Perovskite Nanocrystal Light-Emitting Diodes Enabled by a Universal Crosslinking Method. Adv. Mater. 2016, 28, 3528-3534.

16. Deng, W.; Xu, X.; Zhang, X.; Zhang, Y.; Jin, X.; Wang, L.; Lee, S.-T.; Jie, J. Organometal Halide Perovskite Quantum Dot Light-Emitting Diodes. Adv. Funct. Mater. 2016, 26, 47974802.

17. Liang, D.; Peng, Y.; Fu, Y.; Shearer, M. J.; Zhang, J.; Zhai, J.; Zhang, Y.; Hamers, R. J.; Andrew, T. L.; Jin, S. Color-Pure Violet-Light-Emitting Diodes Based on Layered Lead Halide Perovskite Nanoplates. ACS Nano 2016, 10, 6897-6904.

18. Kumar, S.; Jagielski, J.; Yakunin, S.; Rice, P.; Chiu, Y.-C.; Wang, M.; Nedelcu, G.; Kim, Y.; Lin, S.; Santos, E. J. G.; Kovalenko, M. V.; Shih, C.-J. Efficient Blue Electroluminescence Using Quantum-Confined Two-Dimensional Perovskites. ACS Nano 2016, 10, 9720-9729.

19. Xing, J.; Yan, F.; Zhao, Y.; Chen, S.; Yu, H.; Zhang, Q.; Zeng, R.; Demir, H. V.; Sun, X.; Huan, A.; Xiong, Q. High-Efficiency Light-Emitting Diodes of Organometal Halide Perovskite Amorphous Nanoparticles. ACS Nano 2016, 10, 6623-6630. 
20. Zhang, X.; Lin, H.; Huang, H.; Reckmeier, C.; Zhang, Y.; Choy, W. C. H.; Rogach, A. L. Enhancing the Brightness of Cesium Lead Halide Perovskite Nanocrystal Based Green Light-Emitting Devices through the Interface Engineering with Perfluorinated Ionomer. Nano Lett. 2016, 16, 1415-1420.

21. Ma, G.; Tang, S.-H.; Sun, W.; Shen, Z.; Huang, W.; Shi, J. Size-Dependent Excited State Properties of CdS Nanocrystals. Phys. Lett. A 2002, 299, 581-585.

22. De Quilettes, D. W.; Vorpahl, S. M.; Stranks, S. D.; Nagaoka, H.; Eperon, G. E.; Ziffer, M. E.; Snaith, H. J.; Ginger, D. S. Impact of Microstructure on Local Carrier Lifetime in Perovskite Solar Cells. Science 2015, 348, 683-686.

23. Kwon, W.; Lee, G.; Do, S.; Joo, T.; Rhee, S.-W. Size $\square$ Controlled Soft $\square$ Template Synthesis of Carbon Nanodots toward Versatile Photoactive Materials. Small 2014, 10, 506-513.

24. Im, J.-H.; Jang, I.-H.; Pellet, N.; Grätzel, M.; Park, N.-G. Growth of $\mathrm{CH}_{3} \mathrm{NH}_{3} \mathrm{PbI}_{3} \mathrm{Cuboids}$ with Controlled Size for High-Efficiency Perovskite Solar Cells. Nat. Nanotechnol. 2014, 9, 927-932.

25. Jeon, T.; Jin, H. M.; Lee, S. H.; Lee, J. M.; Park, H. I.; Kim, M. K.; Lee, K. J.; Shin, B.; Kim, S. O. Laser Crystallization of Organic-Inorganic Hybrid Perovskite Solar Cells. ACS Nano 2016, 10, 7907-7914.

26. Tachikawa, T.; Karimata, I.; Kobori, Y. Surface Charge Trapping in Organolead Halide Perovskites Explored by Single-Particle Photoluminescence Imaging. J. Phys. Chem. Lett. 2015, 6, 3195-3201. 
27. Di, D.; Musselman, K. P.; Li, G.; Sadhanala, A.; Ievskaya, Y.; Song, Q.; Tan, Z.-K.; Lai, M. L.; MacManus-Driscoll, J. L.; Greenham, N. C.; Friend, R. H. Size-Dependent Photon Emission from Organometal Halide Perovskite Nanocrystals Embedded in an Organic Matrix. J. Phys. Chem. Lett. 2015, 6, 446-450.

28. Galkowski, K.; Mitioglu, A.; Miyata, A.; Plochocka, P.; Portugall O.; Eperon, G. E.; Wang, J. T.-W.; Stergiopoulos, T.; Stranks, S. D.; Snaith, H. J.; Nicholas, R. J. Determination of the Exciton Binding Energy and Effective Masses for Methylammonium and Formamidinium Lead Tri-Halide Perovskite Semiconductors. Energy Environ. Sci. 2016, 9, 962-970.

29. Brus, L. Electronic Wave Functions in Semiconductor Clusters: Experiment and Theory. $J$. Phys. Chem. 1986, 90, 2555-2560.

30. Kwak, J.; Bae, W. K.; Lee, D.; Park, I.; Lim, J.; Park, M.; Cho, H.; Woo, H.; Yoon, D. Y.; Char, K.; Lee, S.; Lee, C. Bright and Efficient Full-Color Colloidal Quantum Dot LightEmitting Diodes using an Inverted Device Structure. Nano Lett. 2012, 12, 2362-2366.

31. Gonzalez-Carrero, S.; Galian, R. E.; Pérez-Prieto, J. Maximizing the Emissive Properties of $\mathrm{CH}_{3} \mathrm{NH}_{3} \mathrm{PbBr}_{3}$ Perovskite Nanoparticles. J. Mater. Chem. A 2015, 3, 9187-9193.

32. Han, T.-H.; Choi, M.-R.; Woo, S.-H.; Min, S.-Y.; Lee, C.-L.; Lee, T.-W. Molecularly Controlled Interfacial Layer Strategy Toward Highly Efficient Simple $\square$ Structured Organic Light $\square$ Emitting Diodes. Adv. Mater. 2012, 24, 1487-1493.

33. Kim, Y.-H.; Cho, H.; Heo, J. H.; Im, S. H.; Lee, T.-W. Effects of Thermal Treatment on Organic-Inorganic Hybrid Perovskite Films and Luminous Efficiency of Light-Emitting Diodes. Curr. Appl. Phys. 2016, 16, 1069-1074. 
34. Swarnkar, A.; Chulliyil. R.; Ravi. V. K.; Irfanullah. M.; Chowdhury. A.; Nag. A. Colloidal $\mathrm{CsPbBr}_{3}$ Perovskite Nanocrystals: Luminescence beyond Traditional Quantum Dots. Angew. Chem. Int. Ed. 2015, 127, 15644-15648.

35. Li. J.; Xu. L.; Wang. T.; Song. J.; Chen. J.; Xue. J.; Dong. Y.; Cai. B.; Shan. Q.; Han. B.; Zeng. H. 50-Fold EQE Improvement up to $6.27 \%$ of Solution-Processed All-Inorganic Perovskite $\mathrm{CsPbBr}_{3}$ QLEDs via Surface Ligand Density Control. Adv. Mater. 2017. 29, 1603885 .

36. Kim, Y.-H.; Lee, G.-H.; Kim, Y.-T.; Wolf, C.; Yun, H. J.; Kwon, W.; Park, C. G.; Lee, T.W. High Efficiency Perovskite Light-Emitting Diodes of Ligand-Engineered Colloidal Formamidinium Lead Bromide Nanoparticles. Nano Energy 2017, 38, 51-58.

For Table of Contents Only

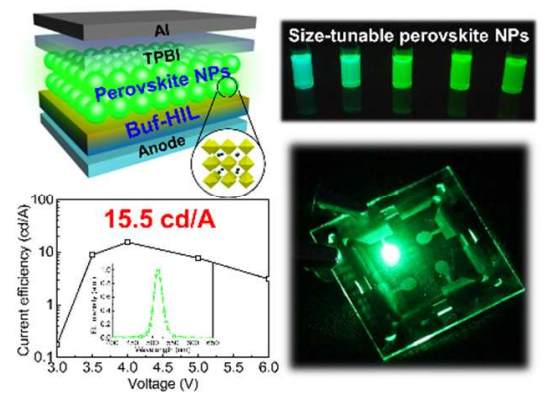

